\title{
Opioid Prescribing and Physician Autonomy: A Quality of Care Perspective
}

\author{
Mark Barnes, JD, LLM $(\mathbb{D} \cdot$ John Giampa, JD, MSPH • Minal Caron, JD
}

Received: 11 September 2018/Accepted: 18 December 2018/Published online: 28 January 2019

(C) Hospital for Special Surgery 2019

Keywords opioid prescribing p professional discipline. quality of care $\cdot$ regulation $\cdot$ peer review

\section{Introduction}

The public health and social harms resulting from misuse of opioids, particularly substance use disorders related to prescription opioids, have been under intense scrutiny in recent years $[9,53]$. Some individuals who receive prescription opioids also use heroin, which has additional risks due to unknown potency and adulteration [7]. Center for Disease Control and Prevention (CDC) statistics indicate that 115 Americans die of an opioid overdose each day [8]. Although the dominant media narrative assigns much of the blame to overprescribing or misprescribing by physicians, the news media less than 20 years ago frequently castigated physicians for failing to provide sufficient pain control and dismissed or ignored the possibility that inappropriate deployment of opioids could lead to addiction [36, 44, 67]. As one article published in American Family Physician in 2000 stated: "Despite recent advances in the understanding of pain management, patients continue to suffer needlessly, primarily because of improper management and inadequate pain medication" $[4,44]$. In 2001, a story appeared in the Chicago Tribune reporting that "[a] jury awarded \$1.5 million to the family of an 85-year-old man who accused his doctor of not prescribing enough pain medication during his final days" [36].

Since then, the narrative has changed. Headlines such as "Who Is Responsible for the Pain-Pill Epidemic?" and "Doctors Increasingly Face Charges for Patient Overdoses"

Electronic supplementary material The online version of this article (https://doi.org/10.1007/s11420-018-09666-8) contains supplementary material, which is available to authorized users.

M. Barnes, JD, LLM · J. Giampa, JD, MSPH · M. Caron, JD ( $ه)$

Ropes \& Gray LLP,

Prudential Tower, 800 Boylston Street,

Boston, MA 02199-3600, USA

e-mail: minal.caron@ ropesgray.com have led physicians in many cases to be extremely cautious in prescribing opioids and lawmakers to impose highly specific restrictions on treatment use of opioids [27, 54]. Legal actions seeking to impose liability on opioid manufacturers for their marketing practices have focused on the alleged effects of those marketing efforts on physician prescribing [74]. Yet, nothing can relieve the responsibility of the physician as the party ultimately responsible for the decision to prescribe a controlled substance. That responsibility is grounded in professional obligations to treat patients appropriately and according to accepted standards of care, violation of which can lead to professional discipline, peer review actions, and quality-assurance measures [4, 54]. This article evaluates the effectiveness of recent legislative mandates and restrictions on opioid prescribing and proposes alternative frameworks for combatting and preventing harms caused by the misuse of prescribed opioids.

\section{Enforcement Mechanisms}

Strategies to address the opioid epidemic have taken a number of different forms. Although the majority of opioid prescribing regulation has taken place at the state level, federal law also imposes restrictions. Drug Enforcement Administration regulations restrict the use of methadone for addiction therapy and create strict administrative requirements for physicians treating addiction with buprenorphine, a partial opioid agonist also used in the treatment of addiction [1].

However, the majority of opioid-restriction legislation has come from state legislatures across the nation. States have, for example, passed laws imposing binding limits on the amount of an opioid that can be prescribed for an initial course of treatment [50]. New York's supply limit statute, which is fairly typical, allows for an initial opioid prescription of 7 days for acute pain [49]. Another intervention implemented in some states is mandated warnings, whereby physicians are required to provide specific information to patients before prescribing opioids [45]. Perhaps the most common intervention, used in nearly all states, is 
prescription drug monitoring programs (PDMPs) [61], which track the prescribing of opioid drugs (often as part of a larger group of tracked drugs) [79]. States vary in the degree to which provider use of the PDMP is mandatory, with a recent trend toward mandatory use [11, 34]. New York's PDMP law requires prescribers to consult the PDMP registry at least 24 hours before prescribing a controlled substance and to document having done so [51]. Some states have imposed mandatory training requirements for physicians on opioid prescribing, including as part of a required continuing medical education program [48]. Additionally, state-level guidelines relating to opioid prescribing have been introduced in many states and are often unusually detailed relative to guidelines applicable to other drugs [57, $78,82]$. Although these guidelines may not always have the force of law, they affect physician decision-making and convey the message that opioids should be considered to be in a separate class from other controlled drugs [11, 34].

Another mechanism of enforcement is the professional discipline system. The practice of medicine in each state is regulated by a board of medicine or similar governing body, which promulgates guidance and rules for physicians licensed in the state and handles enforcement matters, sometimes in conjunction with criminal prosecutors [15]. New York's state board for medicine and the Office of Professional Medical Conduct (OPMC) are the bodies that govern the practice of medicine in New York [3, 47, 62]. The Board for Professional Medical Conduct, which oversees OPMC, is made up of a combination of physician and lay members [84]. OPMC has the authority to impose sanctions on licensed physicians up to and including a permanent surrender of the physician's medical license [46]. If a physician has prescribed opioids inappropriately, which can include prescribing in greater quantities than medically indicated, failing to keep adequate records of prescriptions and the rationale for issuing prescriptions, and failing to monitor patients on an ongoing basis [63-65], OPMC (and its analog agencies in other states) may frame these errors as deviations from the accepted standard of care [23, 63-65]. These state professional discipline systems have frequently suffered from a lack of resources, and commentators have suggested that many state medical boards would benefit from additional resources or other support $[38,39]$.

Professional discipline systems are not the only safeguard against improper prescribing behavior. Other ways in which physicians are held accountable are through the peer review and quality assurance systems. Both peer review and quality assurance are forms of review that, although mandated through certain legal frameworks (such as Medicare Conditions of Participation), are conducted internally within a health care institution or group practice rather than through an external body [2]. Peer review, in which physicians' quality of work is evaluated by other health care providers, is required by the Joint Commission (formerly the Joint Commission on Accreditation of Healthcare Organizations [JCAHO]) $[16,85]$. Through this process, physicians are typically subject to retrospective review of patient records by a peer review committee made up of other physicians $[25,85]$. These peer reviews may be triggered by specific sentinel events or adverse, unexpected outcomes, or may be carried out according to a predetermined review schedule [11,34]. Peer review committees, made up of fellow physicians and other providers, evaluate quality of care on a case-by-case basis and report their findings as to whether the standard of care has been met in particular cases, and then determine the systemic causes of medical errors and identify process improvements $[16,25,11,34]$. Ultimately, quality assurance reports and corrective action plans flow up to the institution's board of directors [11, 34]. Quality assurance is slightly different from peer review in that monitoring is often conducted on an ongoing, systemwide basis, and data are often collected and analyzed by facility administrators and staff, rather than solely by physicians sitting on peer review committees whose primary dayto-day responsibilities are clinical in nature $[14,34]$. In these quality assurance processes, hospital staff collect and analyze performance and outcomes data but can also pinpoint and highlight specific physicians and other providers who appear not to be meeting quality of care standards, and typically propose systems improvements or adjustments to ensure quality care [10,11]. Quality assurance and quality improvement plans may include specific measures relating to opioid prescribing when that prescribing has been identified as a quality of care issue $[17,11,34,68]$.

\section{Legal Interventions}

Researchers have attempted to evaluate the impact of federal and state-level legal interventions relating to opioid prescribing on a variety of health-related outcomes, including overdose deaths, emergency department visits, and quantity of opioid prescriptions.

While PDMPs are thought to reduce opioid misuse by increasing oversight over opioid prescribing and permitting physicians to observe their patients' historical prescription information, evidence of their effectiveness is inconclusive and mixed [23, 29, 30, 42, 43, 52]. A number of studies have concluded that states with PDMPs have not experienced statistically significant differences in the rates of opioid consumption, prescription, or overdose mortality $[4,6,31$, $33,44,66,76,80]$. The literature suggests that PDMPs have led to no discernable or measurable impact on the amount of opioids distributed per capita [6]. Notably, significant reductions in patients that fall in high-risk opioid use categories, such as Medicare beneficiaries, have not been consistently observed [32, 43]. Furthermore, associations have not been established between PDMP prescribing requirements and opioid prescribing decisions [66], and PDMPs have had no effect on the rates of opioid-related visits to emergency departments [32, 42]. However, some of the research on PDMPs suggests more positive outcomes. Some studies have shown that PDMPs have decreased the rates of opioid consumption and overdose mortality [41]. For example, a recent study demonstrated that Florida's PDMP was associated with significant decreases in volume of opioid drugs prescribed; however, the significance of the top-line result was attributable to a reduction in prescribing by "high-risk" 
prescribers, while the PDMP had essentially no effect on "low-risk" prescribers [13, 19]. On the other hand, other studies have found that PDMPs have actually increased the rates of opioid consumption and mortality, as well as rates of use of other illicit drugs $[32,52]$. One study determined that PDMPs dramatically increased the shipment of opioids, a counterintuitive finding [69]. In order to maximize the effectiveness of PDMPs, some researchers have pointed toward implementing PDMPs in conjunction with other comprehensive, and potentially less intrusive, measures, such as patient and physician education [4, 44], integrating multiple PDMPs [6], screening for opioid use, and greater attention to clinical history of a patient's previous or ongoing pain control medications $[33,59]$.

Studies of other interventions have produced similarly varied results. Perhaps because these other interventions are less commonly adopted than PDMPs, the body of research on them is less conclusive and less voluminous. Although several individual studies have indicated that these interventions could have positive results, it may not be possible to come to a firm conclusion on their efficacy based on research conducted to date [32, 37-42]. Studies exploring the effects of prescribing guidelines and limits on prescriptions, for example, have found largely positive results, although these studies often focus on reductions in the amount of drug prescribed, rather than more direct metrics of harm. One study on the effect of prescribing guidelines in an emergency department showed substantial decreases in emergency department visits, as well as decreases in the likelihood of an opioid drug being prescribed and in the amount prescribed when a prescription is issued [55]. Another study examined an emergency department that implemented opioid-specific training and prescribing guidelines, and observed similar decreases in opioid prescriptions [58]. One study that looked at a change in prior authorization rules established by a commercial insurer (limiting opioid prescriptions to a 30-day supply) found that opioid prescribing was reduced upon the institution of such rules, but study authors noted that other factors could have contributed to this effect [26]. Multiple studies have found that prescribing limits had no meaningful effect on health outcomes [5, 32, 43].

Studies evaluating the effects of mandated warnings and required training have also found mixed results. One study reviewed the effectiveness of Risk Evaluation and Mitigation (REMS), a tool used by the FDA to guide prescribing practices and monitor outcomes associated with certain drugs [75]. Although the REMS program for opioid drugs currently does not mandate prescriber training (with the exception of certain transmucosal fentanyl products), even the voluntary REMS guidelines have been shown to decrease rates of prescription of opioids [11, 34]. In another study, a group practice that implemented mandatory training saw decreases in opioid prescribing for chronic pain treatment, but did not see reductions in overall opioid prescribing [73].

\section{Discussion}

Throughout modern medical history, the trust and discretion afforded to physicians have been pillars of the physician- patient relationship. All of the legal interventions discussed above limit physician autonomy and interfere with professional judgment and discretion, thereby restricting this discretion and narrowing a physician's range of options for treating patients. In some situations, as in the public health crisis relating to deaths from opioid misuse, abridging that tradition and imposing rules of general applicability may be indicated, but in adopting specific rules of general applicability, we should also understand what other values and interests may be compromised. In the case of laws and regulations specifically restricting how, when, and under what circumstances all physicians may prescribe opioids to all patients, physician decision-making for the best interest of the patient may be impeded. Apparent solutions of general applicability may result in individual cases of suboptimal medical care.

These types of general restrictions conflict with the more traditional legal mechanisms for ensuring that physicians engage in proper prescribing behavior for all medications, including opioids - namely, peer review and quality improvement activities carried out by health care institutions and physician group practices, and the medical profession's state-level selfregulation through state medical boards. Professional disciplinary bodies are composed of medical professionals and administrators with the knowledge and experience to determine whether individual opioid prescribing behavior fails to adhere to evolving medical standards. State medical boards and peer review committees have longstanding experience in investigating and enforcing behavior that could constitute a deviation from acceptable standards of medical practice, including in complicated areas in which the opinion of the medical community has evolved rapidly, as with opioid prescribing over the past two decades. At the same time, the professional disciplinary process has been criticized for its slowness and for failure to identify and disqualify incompetent physicians or those who engage in unethical, unprofessional, or even criminal behavior $[28,32,77,86]$. These criticisms have been voiced also in regard to failure of this disciplinary process to detect and prevent inappropriate opioid prescribing practices [18, 87]. The answer to these criticisms may lie, however, in making these processes more rigorous and better resourced, in order to deploy their ability to examine individualized physician practices, with careful attention to whether specific prescribing decisions for specific patients have been inappropriate, or even intentionally so. Peer review and quality improvement systems are already powerful tools to ensure quality of patient care and address individual instances of inappropriate provider behavior relating to the prescription of opioids $[12,56,83]$. Such processes could be improved by ensuring a more dedicated focus on proper opioid prescribing practices, particularly with respect to specialty groups such as surgeons, pain management specialists, and psychiatrists. Peer review systems have been occasionally criticized for being ineffective or arbitrary, but studies show measurable improvement associated with implementing and maintaining these systems, including with regard to opioid prescribing [21, 22, 25, 60, 85]. Institutional quality assurance programs can identify and remedy patterns of harmful underprescribing, as well as overprescribing of opioids and other medications. 
In the history of the regulation of medical practice, even in the midst of public health crises, it is unusual that a broad area of practice is pre-empted by legislative or regulatory measures. Specifically, the sort of interference with physician autonomy that these opioid-related legal interventions represent has been used in relation to only a small number of other areas of medical practice. Abortion is a well-known example; states have required physicians to perform sonograms on women seeking abortions [81] or to provide specific state-mandated information to women seeking abortions [72]. These regulations are specific to abortion providers and in several cases have been struck down by courts as being unconstitutionally invasive of the patient's guaranteed right to privacy, including the patient's right to frank communication with her physician [70]. Another state law, ultimately struck down as unconstitutional, prohibited clinicians from asking patients whether they owned firearms [89]. Breast cancer has been the subject of a similar intrusion into physician autonomy, as 16 states require physicians to inform women of surgical options less invasive than bilateral mastectomy, known as breast-conserving surgery or lumpectomy [4]. With these few exceptions, physicians have not experienced areas of practice in which they must consider legal requirements (and the normative message conveyed by such requirements) in rendering their best medical judgment.

Some prominent physicians have publicly opposed specific restrictions on physician judgment in opioid prescribing for pain management, citing their own clinical experience and the scholarship on the topic [35,88]. These concerns - over limiting autonomy and the ability of providers to treat patients in the method they deem most clinically appropriate - must be considered here, as the sum of the evidence described in the scientific literature does not yet point toward any of the detailed regulatory schemes adopted to date as being particularly effective as means of reducing opioid-related harms. As described above, the individual studies that have looked at specific opioid-related initiatives reveal that the most common types of interventions adopted by states have been of limited, or unproven, efficacy.

Additionally, even if the above-described studies had each observed statistically significant results in their primary endpoints, they focused predominantly on endpoints that are limited or misleading in their public health significance, such as the number of individuals receiving prescriptions or the total amount of opioids prescribed. These types of metrics provide a limited view of the overarching public health considerations involved in the opioid crisis. For example, individuals who no longer have access to prescription opioids may move on to using illicit drugs such as heroin, which are associated with a high risk of overdose and other negative health outcomes, although even that risk - of individuals who are prescribed opioids going on to use heroin or other street drugs - may be overstated [1, 53, 71]. Of the many people who use prescription opioids, 4 to $6 \%$ go on to use heroin $[3,7]$. Additionally, there is strong evidence showing that much of the opioid-related harm in recent years has resulted from illicit fentanyl (much of which now comes from outside the USA rather than diversion of domestic supply) [20] and heroin rather than prescription opioids $[11,34]$. Simply reducing the volume of opioids prescribed may address the risks of diversion, but does not necessarily capture whether a legal intervention has the desired ultimate effect on public health [24]. We acknowledge the difficulty of carrying out a study in this arena that could generate clear, unambiguous primary endpoints and direct causal associations. Yet, these highly specific opioid-related legal restrictions on physicians' treatment uses of opioids typically do not accommodate the complex factors that physicians must consider in treating patients, and yet at this point, appear only marginally effective in preventing public health harms from opioid misuse.

Whether intended or unintended, many of these legal interventions have had the effect of reducing access to opioids, not only for the illicit purposes lawmakers are concerned about but also for legitimate uses in the treatment of pain $[47,48,71,88]$. Any regulation that has the effect of reducing the amount of opioids in the system is likely to make it more difficult, and in some cases impossible, for a patient in chronic pain to get the medication he or she needs, creating a parallel "crisis" for some whose pain goes untreated or partially treated $[24,37,52]$. One writer, discussing her personal experience with barriers to access, reported that an alarming number of individuals she knew personally who suffered from pain and were unable to obtain the drugs they needed had committed suicide [25]. It is a genuine and pressing quality of care issue not only that patients may have inappropriate access to medically unnecessary prescription opioids, but it is also a quality of care issue that other patients do not have access to medically necessary and clinically appropriate opioid drugs, whether for the treatment of acute or chronic pain or of addiction.

\section{Conclusion}

Legislators undoubtedly have had the best intentions in drafting laws designed to stem the rising tide of opioid-related addiction and death. However, in many cases, these laws miss the mark. Evidence is mixed on their success in reducing negative health outcomes associated with opioids. In addition to their questionable efficacy, many regulations may be impeding physicians' ability to properly treat their patients' pain and address addiction. Research should focus on whether these legislative restrictions have had positive correlations with reduction in opioid-associated harms, but also on whether these restrictions may have had adverse effects on clinically appropriate care. Both are important questions, but the latter appears to have been studied much less carefully. There are alternative regulatory and quality assurance structures that can be deployed here, including more rigorous hospital and group practice oversight of opioid prescribing practices among their physicians and surgeons, including the specialties of pain management, anesthesiology, primary care, psychiatry, and orthopedics.

Also, the traditional and longstanding self-regulating physician discipline system can be used more aggressively and more effectively to detect, punish, and prevent inappropriate opioid prescribing. That this largely under-resourced system may not have been adequately effective to date does not mean that a more rigorous and robust system could not achieve better results. The professional disciplinary and peer review systems have the advantage of examining physician 
prescribing behavior in individual patient cases, with the appropriateness of those practices calibrated to individual cases and allowing for exceptional patient needs. That sort of calibration and allowance of exceptional cases is not possible in the more specific legal regulations adopted by state legislatures, or even by federal authorities, as in the case of specific restrictions on use of buprenorphine. Physicians who fail to meet the standard of care, whether by overprescribing, prescribing to a patient without a legitimate use for opioids, or failing properly to document such treatment, should have their practices reviewed and adjudicated, just as other physician failures to meet the standard of care are addressed, either by professional bodies or through the peer review processes of hospitals or group practices. Poor physician practices in the prescribing of opioids should not be defended, and should be prevented, and aggressively so. The questions are whether the current legislative focus on decreeing "one size fits all" standards for all physicians in this area is effective, and whether a more robust approach using peer review and professional disciplinary processes can be more effective, while simultaneously more protective of the independence of physician decision making in the interests of individual patients.

Acknowledgments The authors would like to thank Elana Bengualid for her assistance with research in the preparation of this article.

\section{Compliance with Ethical Standards}

Conflict of Interest: Mark Barnes, JD, LLM, is a partner in Ropes and Gray LLP, an international law firm that represents multiple entities in the health care sector, including medical centers and medical schools whose staff and faculty prescribe opioids, as well as pharmaceutical companies that manufacture opioids. The firm represents Mallinckrodt in civil litigation regarding such drugs, although he has not been a member of the litigation teams that have worked on these issues. $\mathrm{He}$ counsels academic medical center and medical school clients about the prescription of opioids consistent with state and federal law. No client of Ropes and Gray had input on the writing, content, or topic of this article. He is co-founder and unpaid faculty co-chair of the MultiRegional Clinical Trials Center of Harvard University and Brigham and Women's Hospital, which is a center for improving ethics and practices in multiregional clinical trials and is funded by grants from various pharmaceutical companies (including Pfizer, Eli Lilly, Novartis, Johnson \& Johnson, Amgen, Sanofi, Biogen, among others), contract research organizations, independent institutional review boards, and the Gates Foundation. Mr. Barnes teaches health law and public health law at Yale Law School and has co-taught at Yale a seminar on the legal issues in the opioid crisis. Minal Caron, JD, is an associate at Ropes and Gray LLP, where he has not been a part of the litigation teams representing Mallinckrodt in civil litigation regarding opioids. John Giampa, JD, MSPH, is an associate at Ropes and Gray LLP, where he has not been a part of the litigation teams representing Mallinckrodt in civil litigation regarding opioids. $\mathrm{Mr}$ Giampa is currently on secondment to the legal department of a major multinational pharmaceutical company that manufactures opioids, among other medications. The Company at which Mr. Giampa is seconded had no input on the writing, content, or topic of this article, and Mr. Giampa's contributions to the article predated his secondment.

Human/Animal Rights: N/A

Informed Consent: N/A
Required Author Forms Disclosure forms provided by the authors are available with the online version of this article.

\section{References}

1. 21 U.S.C. $\S \S 823,827-29$ (West 2012); 21 C.F.R. $\S 1306.04(a)$ (2013); 21 C.F.R. $\S 1305$ et seq. (2013); 42 C.F.R. $\S 8.12$ (2013).

2. 42 C.F.R $\$ 482.12$ (2011); 42 C.F.R $\$ 482.21$ (2011); 42 C.F.R $\$ 482.22(2011)$

3. N.Y. Educ. Law $\S 6520$ et seq.

4. Angelos P, Bedrosian I, Euhus DM, Herrmann VM, Katz SJ, Pusic A. Contralateral prophylactic mastectomy: challenging considerations for the surgeon. Ann Surg Oncol. 2015;22(10):3208-3212.

5. Barnett ML, Gray J, Zink A, Jena A. Coupling policymaking with evaluation - the case of the opioid crisis. $N$ Engl J Med. 2017; 377:2306-2309.

6. Brady J, Wunsch H, DiMaggio C, Lang BH, Giglio J, Li G. Prescription drug monitoring and dispensing of prescription opioids. Public Health Rep. 2014;129(2):139-147.

7. Carlson RG, Nahhas RW, Martins SS, Daniulaityte R. Predictors of transition to heroin use among initially non-opioid dependent illicit pharmaceutical opioid users: a natural history study. Drug Alcohol Depend. 2016; 160:127-134.

8. CDC/NCHS, National Vital Statistics System, Mortality. CDC Wonder, Atlanta: US Department of Health and Human Services, CDC; 2017.

9. Center for Behavioral Health Statistics and Quality (CBHSQ). 2015 National Survey on Drug Use and Health: Detailed Tables. Rockville: Substance Abuse and Mental Health Services Administration; 2016.

10. Centers for Medicare \& Medicaid Services (CMS). Medicare and Medicaid programs; hospital conditions of participation: quality assessment and performance improvement. Final rule. Fed Regist. 2003;68(16):3435-3455.

11. Centers for Medicare and Medicaid Services (n.d.) Guide for Developing a QAPI Plan. Available from https://www.cms.gov/ medicare/provider-enrollment-and-certification/qapi/downloads/ qapiplan.pdf. Accessed 10 Sept 2018.

12. Chan LS, Elabiad M, Zheng L, et al. A medical staff peer review system in a public teaching hospital - an internal quality improvement tool. J Healthc Qual. 2014;36(1):37-44.

13. Chang HY, Lyapustina T, Rutkow L, et al. Impact of prescription drug monitoring programs and pill mill laws on high-risk opioid prescribers: a comparative interrupted time series analysis. Drug Alcohol Depend. 2016;165:1-8.

14. CMS Issues Final Quality Assessment and Performance Improvement Conditions of Participation for Hospitals. The Centers for Medicare \& Medicaid Services - Newsroom. January 23, 2003. Available from https://www.cms.gov/newsroom/press-releases/cms-issues-final-quality-assessment-and-performance-improvement-conditions-participation-hospitals. Accessed 10 Sept 2018.

15. Contact a state medical board. The Federation of State Medical Boards. Available from https://www.fsmb.org/contact-a-statemedical-board. Accessed 10 Sept 2018.

16. Credentialing and Privileging-Requirements for Physician Assistants and Advanced Practice Registered Nurses. The Joint Commission.

17. Crosswalk to Performance Improvement. The Joint Commission.

18. Davis CS, Carr DH. Self-regulating profession? Administrative discipline of "pill mill" physicians in Florida. Subst Abus. 2017;38(3):265-268.

19. Delcher C, Wagenaar AC, Goldberger BA, Cook RL, Maldonado-Molina MM. Abrupt decline in oxycodone-caused mortality after implementation of Florida's prescription drug monitoring program. Drug Alcohol Depend. 2015;150:63-68. 
20. Deprez EE, Hui L, Wills K. Deadly Chinese fentanyl is creating a new era of drug kingpins. Bloomberg. 2018. Available from https://www.bloomberg.com/news/features/2018-05-22/deadlychinese-fentanyl-is-creating-a-new-era-of-drug-kingpins. Accessed 10 Sept 2018.

21. Deyo-Svendsen, Phillips MR, Albright JK, Schilling KA, Palmer, KB. A systematic approach to clinical peer review in a critical access hospital. Qual Manag Health Care. 2016;25(4):213-218.

22. Edwards MT. Clinical peer review program self-evaluation for US hospitals. Am J Med Qual. 2010;25(6):474-480.

23. Finley E, Garcia A, Rosen K, McGeary D, Pugh MJ, Potter JS. Evaluating the impact of prescription drug monitoring program implementation: a scoping review. BMC Health Serv Res. 2017;17(1):420.

24. Fudin J, Atkinson TJ. Opioid prescribing levels off, but is less really more? Pain Medicine. 2014;15(2):184-187.

25. Fuqua A. The other opioid crisis: pain patients who cannot access the medicine we need. Washington Post. 2018. Available from https:// www.washingtonpost.com/outlook/the-other-opioid-crisis-pain-patients-who-cant-access-the-medicine-they-need/2018/03/09/5ad83b242301-11e8-badd-7c9f29a55815 story.html. Accessed 10 Sept 2018.

26. García MC, Dodek AB, Kowalski T, et al. Declines in opioid prescribing after a private insurer policy change-Massachusetts, 2011-2015. MMWR Morb Mortal Wkly Rep. 2016;65:1125-1131.

27. Gounder C. Who is responsible for the pain-pill epidemic? New Yorker. 2013. Available from https://www.newyorker.com/business/currency/who-is-responsible-for-the-pain-pill-epidemic. Accessed 10 Sept 2018.

28. Grant D, Alfred KC. Sanctions and recidivism: an evaluation of physician discipline by state medical boards. $J$ Health Polit Policy Law. 2007;32(5):867-885.

29. Griggs C, Weiner S, Feldman J. Prescription drug monitoring programs: examining limitations and future approaches. West $J$ Emerg Med. 2015;16(1):67-70.

30. Haegerich TM, Paulozzi LJ, Manns BJ, Jones CM. What we know, and do not know, about the impact of state policy and systems-level interventions on prescription drug overdose. Drug Alcohol Depend. 2014;145:34-47.

31. Haffajee R. Preventing opioid misuse with prescription drug monitoring programs: a framework for evaluating the success of state public health laws. Hastings Law Journal. 2016;67(6):1621-1694

32. Harris JA, Byhoff E. Variations by state in physician disciplinary actions by US medical licensure boards. BMJ Qual Saf. 2017;26(3):200-208.

33. Hawk K, D’Onofrio G, Fiellin DA, et al. Past-year prescription drug monitoring program opioid prescriptions and self-reported opioid use in an emergency department population with opioid use disorder. Acad Emerg Med. 2018;25(5):508-516.

34. Centers for Medicare and Medicaid Services (n.d.). Hospital Quality Assessment Performance Improvement (QAPI) Worksheet. Available from https://www.cms.gov/Medicare/Provider-Enrollment-and-Certification/SurveyCertificationGenInfo/ Downloads/Survey-and-Cert-Letter-15-12-Attachment-2.pdf. Accessed 10 Sept 2018.

35. Inserro A. Doctors wait to see how CMS' opioid changes play out for patients in pain. AJMC Managed Markets Network. 2018. https:/ www.ajmc.com/newsroom/doctors-wait-to-see-how-cms-opioidchanges-play-out-for-patients-in-pain. Accessed 10 Sept 2018.

36. Jury awards $\$ 1.5$ million in suit over untreated pain. Chicago Tribune. 2001. Available from https://www.chicagotribune.com/ news/ct-xpm-2001-06-15-0106150039-story.html. Accessed 10 Sept 2018.

37. Knudsen HK, Havens JR, Lofwall MR, Studts JL, Walsh SL. Buprenorphine physician supply: relationship with state-level prescription opioid mortality. Drug Alcohol Depend. 2017;173 Suppl 1:S55-S64.

38. Law MT, Hansen ZK. Medical licensing board characteristics and physician discipline: an empirical analysis. J Health Polit Policy Law. 2010;35(1):63-93.

39. Leibert M. Performance of state medical boards: implications for hospitals and health systems. Hosp Top. 2010;88:4:107-115.
40. Federation of State Medical Boards 2018 Leveraging Growth: 2018 Annual Report. Available from https://www.fsmb.org/ siteassets/advocacy/publications/fsmb-current-annual-report.pdf. Accessed 10 Sept 2018.

41. Lyapustina T, Rutkow L, Chang HY, et al. Effect of a "pill mill" law on opioid prescribing and utilization: the case of Texas. Drug Alcohol Depend. 2016;159:190-197.

42. Maughan B, Bachhuber MA, Mitra N, Starrels JL. Prescription monitoring programs and emergency department visits involving opioids, 2004-2011. Drug Alcohol Depend. 2015;156:282-288.

43. Meara E, Horwitz J, Powell W, et al. State legal restrictions and prescription-opioid use among disabled adults. $N$ Engl J Med. 2016; 375:44-53.

44. Miller KE. Physician attitudes a barrier to pain management. Am Fam Physician. 2000;62(10):2317-2318.

45. N.J. Stat. Ann. § 24:21-15.1.

46. N.Y. Pub. Health Law $\S 230$.

47. N.Y. Pub. Health Law $\S 230 ; \S$ N.Y. Educ. Law $\S 6532$.

48. N.Y. Pub. Health Law $\S 3309-a(3)$.

49. N.Y. Pub. Health Law $\S 3331(5)(b)$.

50. N.Y. Pub. Health Law § 3331(5).

51. N.Y. Pub. Health Law Article 33.

52. Nam YH, Shea DG, Shi Y, Moran JR. State prescription drug monitoring programs and fatal drug overdoses. Am J Manag Care. 2017;23(5):297-303.

53. National Academies of Sciences, Engineering, and Medicine; Health and Medicine Division; Board on Health Sciences Policy; Committee on Pain Management and Regulatory Strategies to Address Prescription Opioid Abuse. Phillips JK, Ford MA, Bonnie RJ, editors. Pain management and the opioid epidemic: balancing societal and individual benefits and risks of prescription opioid use. Washington (DC): National Academies Press (US) 2017. 4, Trends in opioid use, harms, and treatment. Available from https:/www.ncbi.nlm.nih.gov/books/NBK458661. Accessed 10 Sept 2018.

54. Nedelman M. Doctors increasingly face charges for patient overdoses. CNN. 2017. Available from https:/www.cnn.com/2017/ 07/31/health/opioid-doctors-responsible-overdose/index.html. Accessed 10 Sept 2018.

55. Neven D, Paulozzi L, Howell D, et al. A randomized controlled trial of a citywide emergency department care coordination program to reduce prescription opioid related emergency department visits. J Emerg Med. 2016;51(5):498-507.

56. Nolan SW, Burkard JF, Clark MJ, Davidson JE, Agan DL. Effect of morbidity and mortality peer review on nurse accountability and ventilator-associated pneumonia rates. J Nurs Adm. 2010;40(9):37483.

57. Opioid Treatment Guidelines and Other Information for Health Care Professionals and Patients Center for Disease Control and Prevention. NY State: Department of Health. Available from https:// www.health.ny.gov/professionals/narcotic/opioid treatment guidelines. Accessed 10 Sept 2018.

58. Osborn SR, Yu J, Williams B, Vasilyadis M, Blackmore CC. Changes in provider prescribing patterns after implementation of an emergency department prescription opioid policy. J Emerg Med. 2017;52(4):538-546.

59. Paone D, Tuazon E, Kattan J, et al. Decrease in rate of opioid analgesic overdose deaths - Staten Island, New York City, 20112013. MMWR Morb Mortal Wkly Rep. 2015;64(18):491-494.

60. Penti B, Liebschutz JM, Kopcza B, Xuan Z, Odell C, Saper R. Novel peer review method for improving controlled substance prescribing in primary care. J Opioid Manag. 2016;12(4):269-279.

61. N.Y. Pub. Health Law § 3343-a; 10 NYCRR § 80.63; Fla. Stat. $\S 893.055$ (2018); 37 Tex. Admin. Code $\S \S 13.71-86$ (West 2005).

62. Physician and Physician Assistants Disciplinary and Other Actions. Department of Health. NY State: Department of Health. Revised July 2012.

63. Physician Information (Arthur Mercado). NY State: Department of Health.

64. Physician Information (Gregory Denzel). NY State: Department of Health. 
65. Physician Information (Liviu Nastase). NY State: Department of Health.

66. Pomerleau AC, Nelson LS, Hoppe JA, Salzman M, Weiss PS, Perrone J. The impact of prescription drug monitoring programs and prescribing guidelines on emergency department opioid prescribing. Pain Med. 2017;18(5):889-897.

67. Porter J, Hershel J. Addiction rare in patients treated with narcotics. N Engl J Med. 1980;302:123.

68. Quality Assessment and Performance Improvement (QAPI) Program Description. Peach State Health Plan: 2017.

69. Reisman RM, Shenoy PJ, Atherly AJ, Flowers CR. Prescription opioid usage and abuse relationships: an evaluation of state prescription drug monitoring program efficacy. Subst Abuse. 2009;3:41-51.

70. Roe v. Wade and the right to abortion. National Women's Law Center. January 18, 2018.

71. Rose ME. Are prescription opioids driving the opioid crisis? Assumptions vs. facts Pain Medicine. 2017;19(4):793-807.

72. S.D. Codified Laws § 34-23A-10.1; Mo. Ann. Stat. § 188.039.

73. Saunders K, Shortreed S, Thielke S, et al. Evaluation of health plan interventions to influence chronic opioid therapy prescribing. Clin J Pain. 2015;31(9):820-829.

74. Semeuls A. Are pharmaceutical companies to blame for the opioid epidemic? The Atlantic. 2017. Available from https:// www.theatlantic.com/business/archive/2017/06/lawsuit-pharmaceutical-companies-opioids/529020. Accessed 10 Sept 2018.

75. Soelberg CD, Brown RE Jr., Du Vivier D, Meyer JE, Ramachandran BK. The US opioid crisis: current federal and state legal issues. Anesth Analg. 2017;125(5):1675-1681.

76. Spooner L, Fernandes K, Martins D, et al. High-dose opioid prescribing and opioid-related hospitalization: a populationbased study. PLOS One. 2016;12(1):e0170834.

77. State Medical Board Is Too Slow. The Hartford Courant. July 23, 2013. Available from https://www.courant.com/opinion/editorials/hc-xpm-2013-07-23-hc-ed-medical-board-must-speed-up20130723-story.html. Accessed 10 Sept 2018.
78. State Opioid Prescribing Policy: Florida. Florida Academy of Pain Medicine.

79. Substance Abuse and Mental Health Services Administration. Prescription drug monitoring programs: a guide for healthcare providers. In Brief. 2017;10:1.

80. Sun BC, Charlesworth CJ, Lupulescu-Mann N, et al. Effect of automated prescription drug monitoring program queries on emergency department opioid prescribing. Ann Emerg Med. 2018;71(3):337-347.e6.

81. Tex. Health \& Safety Code Ann. § 171.012; Wis. Stat. Ann. § 253.10 .

82. Texas Medical Association House of Delegates: Responsible Opioid Prescribing for Pain Management. Texas Pain Society. Available from https://www.texaspain.org/assets/ resolution313.pdf. Accessed 10 Sept 2018.

83. Tricco AC, Ivers NM, Grimshaw JM, et al. Effectiveness of quality improvement strategies on the management of diabetes: a systematic review and meta-analysis. Lancet. 2012;379(9833):2252-2261.

84. Understanding New York's Medical Conduct Program-Physician Discipline. NY State: Department of Health. Revised March 2016. Available from https://www.health.ny.gov/publications/1445. Accessed 10 Sept 2018.

85. Vyas D, Hozain AE. Clinical peer review in the United States: history, legal development and subsequent abuse. World $J$ Gastroenterol. 2014;20(21):6357-6363.

86. Wadhwani A. Tennessee sometimes takes years to discipline doctors. Tennessean. 2015. Available from https:// www.tennessean.com/story/news/2015/10/12/state-lags-behinddoctor-discipline/73817306/. Accessed 10 Sept 2018.

87. Waisbren SJ. The opioid epidemic and the Minnesota Board of Medical Practice. Minn Med. 2016;99(3):39-41.

88. Webster L. The pain epidemic versus the opioid crisis; in Worley SL. New directions in the treatment of chronic pain: National pain strategy will guide prevention, management, and research. PT. 2016;41:107-115.

89. Wollschlaeger v. Governor, Fla., 848 F.3d 1293 (11th Cir. 2017). 